\title{
Multivitaminpräparate
}

\section{Sind sie bei geriatrischen Patienten sinnvoll?}

\section{Frage von Dr. med. A. Bankstahl, Winterberg:}

Ist eine Supplementierung von Multivitaminpräparaten und Spurenelementen bei geriatrischen Patienten, bei denen aus verschiedenen Gründen (Demenz, Immobilität, auch finanzielle Einschränkungen) eine optimale Versorgung mit Vitaminen und Spurenelementen nicht möglich ist, vertretbar und welche Anforderungen sind an eine solche Supplementierung zu stellen?

\section{Antwort von Prof. Dr. D. Volkert Nürnberg:}

Grundsätzlich ist davon auszugehen, dass Vitamine, Mineralstoffe und Spurenelemente - die sogenannten Mikronährstoffe - in einer vielseitigen, abwechslungsreichen und mengenmäBig adäquaten Ernährung in ausreichenden Mengen enthalten sind. Auch alte Menschen können so ihren täglichen Bedarf decken.

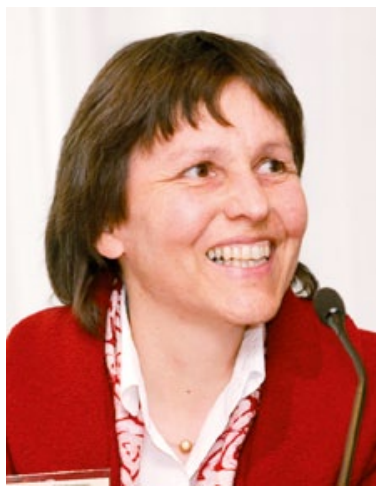

Prof. Dr. Dorothea Volkert, Nürnberg.
Wenn ältere Menschen aus unterschiedlichsten Gründen
Probleme mit der Ernährung bekommen, betrifft dies meist nicht nur die Mikronährstoffe, sondern die Ernährung insgesamt: Die Essmenge ist reduziert, es werden nur kleine Portionen gegessen und es fehlen folglich nicht nur Mikro- sondern auch Makronährstoffe (Protein, Fett, Kohlenhydrate) und Energie. In dieser Situation sollten nicht nur Vitamine, Mineralstoffe und Spurenelemente, sondern auch Energie und Protein supplementiert werden. Dies ist in Form von bilanzierter Trinknahrung effektiv möglich [1].

Eine Supplementierung mit Mikronährstoffen ist prinzipiell immer dann gerechtfertigt, wenn speziell diese Nährstoffe längerfristig nicht in bedarfsgerechter Menge mit der üblichen Nahrung aufgenommen werden können. Dies kann der Fall sein, wenn die Ernährung kalorisch ausreichend, aber sehr einseitig ist, z.B. bestimmte Lebensmittelgruppen wie frisches Obst und Gemüse oder

\section{Welche sind aktiver und wirksamer?}

Industriell „künstlich“ hergestellte Vitamine sind von ihrer chemischen Struktur identisch mit den natürlich vorkommenden Vitaminen, und es ist folglich davon auszugehen, dass sie grundsätzlich genauso „aktiv“ und wirksam sind. Allerdings kommen einige Vitamine natürlicherweise in Lebensmitteln in verschiedenen Formen vor, die biologisch unterschiedlich wirksam sind (z. B. Folsäure und verschiedene Folate), in Vitaminpräparaten ist jedoch meist nur eine dieser Formen enthalten. Dieser Tatsache wird jedoch durch Berechnung von Vitamin-Äquivalenten (z.B. Folat-Äquivalente) Rechnung getragen.

Dem Verzehr von Lebensmitteln sollte aber im Vergleich zur Einnahme isolierter Nährstoffe in Form von Präparaten immer der Vorzug gegeben werden.

D. VOLKERT

Milchprodukte in der Ernährung fehlen. Auch bei längerfristiger Breikost kann die Ernährung einseitig und die Mikronährstoffversorgung gefährdet sein. In diesen Fällen sollte idealerweise eine qualifizierte Ernährungsfachkraft (Diätassistent/in, Ökotrophologe/in mit Zertifikat für Ernährungsberatung) einbezogen werden, die die Ernährungsgewohnheiten analysiert, Art und Ausmaß der Defizite konkretisiert und Möglichkeiten der Verbesserung aufzeigt.

Lassen sich die Ernährungsgewohnheiten nicht verbessern, kann die Einnahme von Mikronährstoffen sinnvoll sein, um einem Mangel vorzubeugen. Hierzu empfehlen sich Kombinationspräparate (Multivitamin-MineralstoffPräparate) mit Nährstoffmengen im Bereich der Tageszufuhrempfehlungen der Deutschen Gesellschaft für Ernährung (DGE) [2]. Bei ausgeprägten Defiziten müssen höhere Dosierungen gewählt werden.

Aufgrund des bisher fraglichen Nutzens und nicht auszuschließender unerwünschter Nebeneffekte insbesondere bei hoher Dosierung, kann eine generelle routinemäßige und unkontrollierte Einnahme von Multivitamin-Mineralstoff-Präparaten auch für gebrechliche ältere Menschen derzeit nicht empfohlen werden.

1. Milne AC, Potter J, Vivanti A, Avenell A. Protein and energy supplementation in elderly people at risk from malnutrition. Cochrane Database Syst Rev. 2009 Apr 15; (2): CD003288

2. http://www.dge.de/modules.php?name=Cont ent $\&$ pa $=$ showpage $\&$ pid=3\&page $=1$.

- Prof. Dr. rer. nat. Dorothea Volkert, Universität Erlangen-Nürnberg, Heimerichstraße 58, D-90419 Nürnberg 